\title{
Jogo MICROH2O: ferramenta de estudo para a Microbiologia da Água dentro do
}

\section{Ensino Fundamental - anos finais}

\author{
MICROH2O Game: study tool for Water Microbiology in Elementary School - final years \\ Juego MICROH2O: herramienta de estudio para la Microbiología del Agua en la Escuela Primaria \\ - últimos años
}

Recebido: 24/03/2021 | Revisado: 29/03/2021 | Aceito: 01/04/2021 | Publicado: 12/04/2021

\author{
Isadora Martins Pereira \\ ORCID: https://orcid.org/0000-0002-5821-9131 \\ Universidade Estadual do Ceará, Brasil \\ E-mail: isadora.martins@aluno.uece.br \\ Roselita Maria de Souza Mendes \\ ORCID: https://orcid.org/0000-0003-0705-2914 \\ Universidade Estadual do Ceará, Brasil \\ E-mail: roselita.mendes@uece.br \\ Maria Elane de Carvalho Guerra \\ ORCID: https://orcid.org/0000-0002-4649-4769 \\ Universidade Estadual do Ceará, Brasil \\ E-mail: elane.guerra@uece.br \\ Bruno Edson-Chaves \\ ORCID: https://orcid.org/0000-0001-6031-5336 \\ Universidade Estadual do Ceará, Brasil \\ E-mail: bruno.edson@uece.br \\ Eliseu Marlônio Pereira de Lucena \\ ORCID: https://orcid.org/0000-0002-8190-1702 \\ Universidade Estadual do Ceará, Brasil \\ E-mail: eliseu.lucena@uece.br \\ Oriel Herrera Bonilla \\ ORCID: https://orcid.org/0000-0002-9140-6086 \\ Universidade Estadual do Ceará, Brasil \\ E-mail: oriel.herrera@uece.br \\ Lydia Dayanne Maia Pantoja \\ ORCID: https://orcid.org/0000-0002-4446-7230 \\ Universidade Estadual do Ceará, Brasil \\ E-mail: lydia.pantoja@uece.br
}

\begin{abstract}
Resumo
A abordagem conteudista relacionada a Microbiologia da Água aperfeiçoa a formação da consciência ambiental no aluno. O uso de jogos educativos visa auxiliar no processo de ensino-aprendizagem e estimular uma conexão com o tema abordado. Neste contexto, objetivou-se descrever o processo de construção e avaliação de um jogo como mecanismo facilitador do ensino da Microbiologia da Água. Trata-se de uma pesquisa quali-quantitativa, onde foi confeccionado um jogo de tabuleiro, avaliado via questionário junto a especialistas, também foi aplicado a turmas do $7^{\circ}$ ano de duas escolas da Região Metropolitana de Fortaleza-CE, sendo avaliado através da elaboração de desenhos descritivos pelos alunos. Cinco especialistas apontaram melhorias, em especial, na jogabilidade, coloração e informações mais explícitas no manual. Após as melhorias, o jogo foi aplicado a trinta alunos e constatou-se que 79,8\% deles conseguem perceber problemas do cotidiano que são conectados à temática e 53,5\% demonstram através de seus traços e cores. Dessa forma, conclui-se que utilizar o jogo didático para abordar conteúdos transversais ao conteúdo ministrado no Ensino Fundamental - anos finais, permite estimular o interesse a disciplina e assim tornar o discente protagonista em seu processo de ensino-aprendizagem.
\end{abstract}

Palavras-chave: Ensino de ciências; Educação básica; Recurso didático.

\section{Abstract}

The content approach related to Water Microbiology improves the formation of environmental awareness in the student. The use of educational games aims to assist in the teaching-learning process and encourage a connection with the topic addressed. In this context, the objective was to describe the process of building and evaluating a game as a facilitating mechanism for the teaching of Water Microbiology. It is a qualitative and quantitative research, in which a board game was made, evaluated by a questionnaire with specialists, it was also applied to 7th grade classes in two schools in the Metropolitan Region of Fortaleza-CE, being evaluated through the elaboration of descriptive drawings by students. Five 
experts pointed out improvements, in particular, in the gameplay, coloring and more explicit information in the manual. After the improvements, the game was applied to thirty students and it was found that $79.8 \%$ of them are able to perceive everyday problems that are connected to the theme and 53.5\% demonstrate it through their lines and colors. Thus, it is concluded that using the didactic game to approach content transversal to the content taught in Elementary School final years, allows to stimulate interest in the discipline and thus make the student protagonist in his teaching-learning process.

Keywords: Science teaching; Basic education; Didactic resource.

\section{Resumen}

El enfoque de contenido relacionado con la Microbiología del Agua mejora la formación de la conciencia ambiental en el alumno. El uso de juegos educativos tiene como objetivo ayudar en el proceso de enseñanza-aprendizaje y fomentar una conexión con el tema abordado. En este contexto, el objetivo fue describir el proceso de construcción y evaluación de un juego como mecanismo facilitador para la enseñanza de la Microbiología del Agua. Se trata de una investigación cualitativa y cuantitativa, en la cual se realizó un juego de mesa, evaluado mediante un cuestionario con especialistas, también se aplicó a clases de 7mo grado en dos escuelas de la Región Metropolitana de Fortaleza-CE, siendo evaluado mediante la elaboración de descriptivos dibujos de estudiantes. Cinco expertos señalaron mejoras, en particular, en la jugabilidad, los colores y una información más explícita en el manual. Luego de las mejoras, se aplicó el juego a una treintena de alumnos y se encontró que el $79.8 \%$ de ellos son capaces de percibir problemas cotidianos que están relacionados con la temática y el $53.5 \%$ lo demuestra a través de sus líneas y colores. Así, se concluye que utilizar el juego didáctico para abordar contenidos de forma transversal a los contenidos impartidos en la Educación Primaria últimos cursos, permite estimular el interés por la disciplina y así hacer al alumno protagonista en su proceso de enseñanza-aprendizaje.

Palabras clave: Enseñanza de las ciencias; Educación básica; Recurso didáctico.

\section{Introdução}

Inserir o estudo da Microbiologia da Água no currículo de Ciências e Biologia vai além do conhecimento dos microrganismos, atingindo a realidade de cada aluno. É necessário conhecer a microbiota existente na água para difundir que não existem apenas os aspectos negativos e, sim, que é possível encontrar diversos microrganismos que auxiliam em funções importantes para a manutenção da vida (Kimura et al., 2013).

Permitir que essa temática aborde aspectos econômicos, sociais e ambientais, possibilita ao aluno um pensamento mais reflexivo sobre questões de seu cotidiano que envolvam esse tema. Nos últimos anos, discutir mais sobre os variados conteúdos ligados a água desde conceitos até ações realizadas para sua preservação, se torna necessário para desenvolver neles conhecimentos críticos para que futuramente possam ser capazes de debater sobre a questão socioambiental hídrica instaurada no mundo (Azevedo et al., 2018).

O ensino de Microbiologia pode apresentar dificuldades de conexão com a situação vivenciada pelos alunos, já que os conteúdos da disciplina podem exigir uma maior compreensão de fenômenos pouco visuais, que podem ser facilitados com o uso de imagens, gifs animados e recursos audiovisuais. Assim, abordar um tema transversal ao conteúdo ensinado no Ensino Fundamental, nos permite uma prática docente que inclua novas metodologias ao processo de ensino-aprendizagem tornando-o mais prático e individual de cada aluno (Bôas et al., 2018).

Diante de um assunto pertinente como este, se faz necessário conectá-lo a outras vertentes dentro do ensino de Ciências e Biologia, a fim de permitir que o estudo desse tema seja realizado também através da interação com novos conteúdos. Englobar a temática de Microbiologia da Água dentro desse processo permite ampliar a concepção de ensino tradicional administrado nas escolas.

O conteúdo abordado pela Microbiologia que quase sempre é transmitido por meio de aulas teóricas e conteudistas o que acaba despertando no aluno uma abstração atrelada a esse conteúdo, dificultando o processo de ensino aprendizagem dos discentes. Sendo assim, o aluno do Ensino Fundamental - anos finais, acompanham as matérias mais abstratas de uma maneira mais superficial e muitas vezes acabam agregando a temática as notícias propagadas pelo senso comum (Medeiros et al., 2017).

Assim, se faz de suma importância introduzir práticas ligadas as Ciências, como atividades experimentais, que tirem o 
aluno de sua zona de conforto e proporcione aproximação desse conhecimento científico por meio da ligação com suas experiências extraclasse. De forma que, não só as aplicações das competências e habilidades sejam realizadas, mas também seja concretizado um estudo e planejamento para estas serem conhecidas pelos professores, evitando possíveis falhas que envolvam a explicação dos conteúdos sobre água dentro da área de Ciências (Compiani, 2018).

Desse modo, há uma gama de jogos disponíveis para serem utilizados no processo de aprendizagem de uma temática a ser vista em sala de aula. Jogos educativos aplicados ao ensino tem como foco na produção de um material educacional que sirva de apoio durante a exposição dos conteúdos curriculares definidos para cada ano, se tornando um material de estudo para as mais diversas disciplinas (Campos, 2018).

O uso de métodos lúdicos vem se tornando cada vez mais importante no âmbito escolar atual, pois estabelece uma relação íntima entre a experiência do aluno e o conteúdo abordado tornando o aprendizado mais significativo, leve e interessante. Utilizá-los de forma efetiva e dinâmica em sala de aula pode possibilitar que a metodologia selecionada obtenha resultados positivos na participação, para que os alunos tenham confiança e interesse no aprofundamento ao conteúdo, adquirindo assim conhecimentos mais avançados sobre o assunto (Pascotto et al., 2020).

E os jogos de tabuleiro são um dos tipos de jogos didáticos mais usados como tática para o ensinar. Eles agem por meio da instigação dos jogadores através de provas, questionamentos com relação à temática, competências, revisão de conteúdo, entre outras maneiras que mesclam a interação entre os jogadores e dispõem-se a agregar o senso de responsabilidade ao processo de aprendizagem por meio da integração dos conhecimentos entre os participantes (Fuzeto et al., 2018).

Com o passar do tempo, jogos didáticos foram sendo incorporados com características mais complexas e que permitem um avanço nos conteúdos abordados agregando informações durante sua evolução e desenvolvimento no decorrer dos anos, auxiliando na construção e no desenvolvimento da inteligência de seus produtores e participantes (Campos, 2018).

Dentro desse contexto, objetivou-se descrever o processo de construção e avaliação de um jogo didático como mecanismo facilitador do ensino da temática Microbiologia da Água para o Ensino Fundamental II.

\section{Metodologia}

A pesquisa é experimental de abordagem mista, quantitativa e qualitativa, caracteriza-se por utilizar de alguns itens para interferir nas respostas e com essa interferência analisar uma provável relação estabelecida entre os aspectos e as informações fornecidas pelo público, além de utilizar outros meios que permitam a participação e interação do público alvo, visando enxergar o sucesso ou insucesso dessa pesquisa, em um grau mais pessoal, tornando a abordagem mais completa (Manzato \& Santos, 2012; Santos et al., 2017; Creswell, 2021).

Este trabalho se consolidou por meio de uma análise de percepção do jogo por especialistas e pelos próprios alunos, tendo a produção do instrumento didático (jogo) como parte crucial desse processo, pois este serviu como ferramenta para ministrar o conteúdo programático.

A escolha das escolas (Escola A e Escola B) surgiu a partir das vivências adquiridas durante a disciplina de Estágio Supervisionado do Ensino Fundamental, que foi vivenciado na Região Metropolitana de Fortaleza e por ter conseguido desenvolver as atividades exigidas pelo cronograma da disciplina sem restrições e com muita receptividade dos discentes das escolas.

O público alvo foram alunos do $7^{\circ}$ ano do Ensino Fundamental II, pois o conteúdo de Microbiologia da Água encaixase com conteúdo programático da série, de uma escola pública e de uma escola particular da Caucaia, Região Metropolitana de Fortaleza-Ceará.

A confecção foi composta de duas etapas principais: seleção do conteúdo abordado dentro do jogo e a organização da ferramenta didática, onde foram levados em consideração temas, formas e percepções a fim de ser realizada da maneira didática 
a construção física do jogo. O jogo abordou o tema de Microbiologia da Água aplicado ao cotidiano, seguindo a recomendação do Programa Nacional do Livro Didático (PNLD) para o Ensino Fundamental II, ressalta-se que esta recomendação é válida pelo período de três anos consecutivos (2017 a 2019).

A ferramenta foi baseada nos jogos War e Floresta Encantada da empresa Grow®, e no jogo Show do Milhão da empresa Estrela ${ }^{\circledR}$, já conhecidos no mercado lúdico; o tabuleiro passou pelos devidos ajustes para acomodação da temática e do público alvo. Também foram utilizados o máximo possível de materiais recicláveis, materiais adaptados de outros jogos, cola e impressões coloridas.

A avaliação foi realizada por um grupo de cinco especialistas, três especialistas em conteúdo e dois especialistas em jogos, que foram selecionados por atenderem a no mínimo dois pré-requisitos estabelecidos por Costa et al. (2018), os quais são: serem peritos na área de jogos ou desenvolverem trabalho com água durante um período mínimo de 3 anos; serem titulados na área da Educação ou em áreas afins; exercerem algum vínculo com o Curso de Ciências Biológicas, Engenharia Ambiental e áreas afins, além de realizar produção científica sobre o tema por mais de 2 anos e ter tempo de atuação mínimo de 3 anos com a temática em discussão.

O questionário foi constituído por blocos, divididos em: Caracterização sociodemográfica, Estrutura do jogo, Linguagem do jogo, Conteúdo do jogo, Ferramenta de ensino e Considerações sobre o jogo. A formulação do mesmo utilizou a escala de Likert como forma de avaliação e embasou-se estruturalmente nas obras de Ramos et al. (2019) e Manzato e Santos (2012). Essa avaliação foi realizada na perspectiva de disponibilizar o jogo já melhorado ao público-alvo. Os dados referentes aos questionários juntos aos especialistas foram analisados, interpretados e sintetizados por meio de frequências simples e relativas.

A aplicação ocorreu com a turma dividida em dois grupos para melhorar o aproveitamento do jogo e ao fim do mesmo foi solicitado que cada aluno produzisse um desenho sobre a percepção deles frente ao entendimento do jogo e ao conteúdo abordado, além de ser permitida a escrita de palavras-chave dentro do espaço gráfico do desenho. Os desenhos feitos pelos alunos foram interpretados através de esquema de análise gráfica (Quadro 1) que foi baseado em obra de Silva et al. (2016) com adaptações através de critérios de presença ou ausência de elementos gráficos a fim de facilitar a interpretação. Já as palavras escritas no desenho foram analisadas por meio de nuvens de palavras, construídas por intermédio do programa Wordcloud®. 
Quadro 1. Esquema de análise gráfica a ser utilizada para interpretação dos desenhos produzidos por alunos do $7^{\circ}$ ano do Ensino Fundamental em escolas de Caucaia na Região Metropolitana de Fortaleza-Ceará.

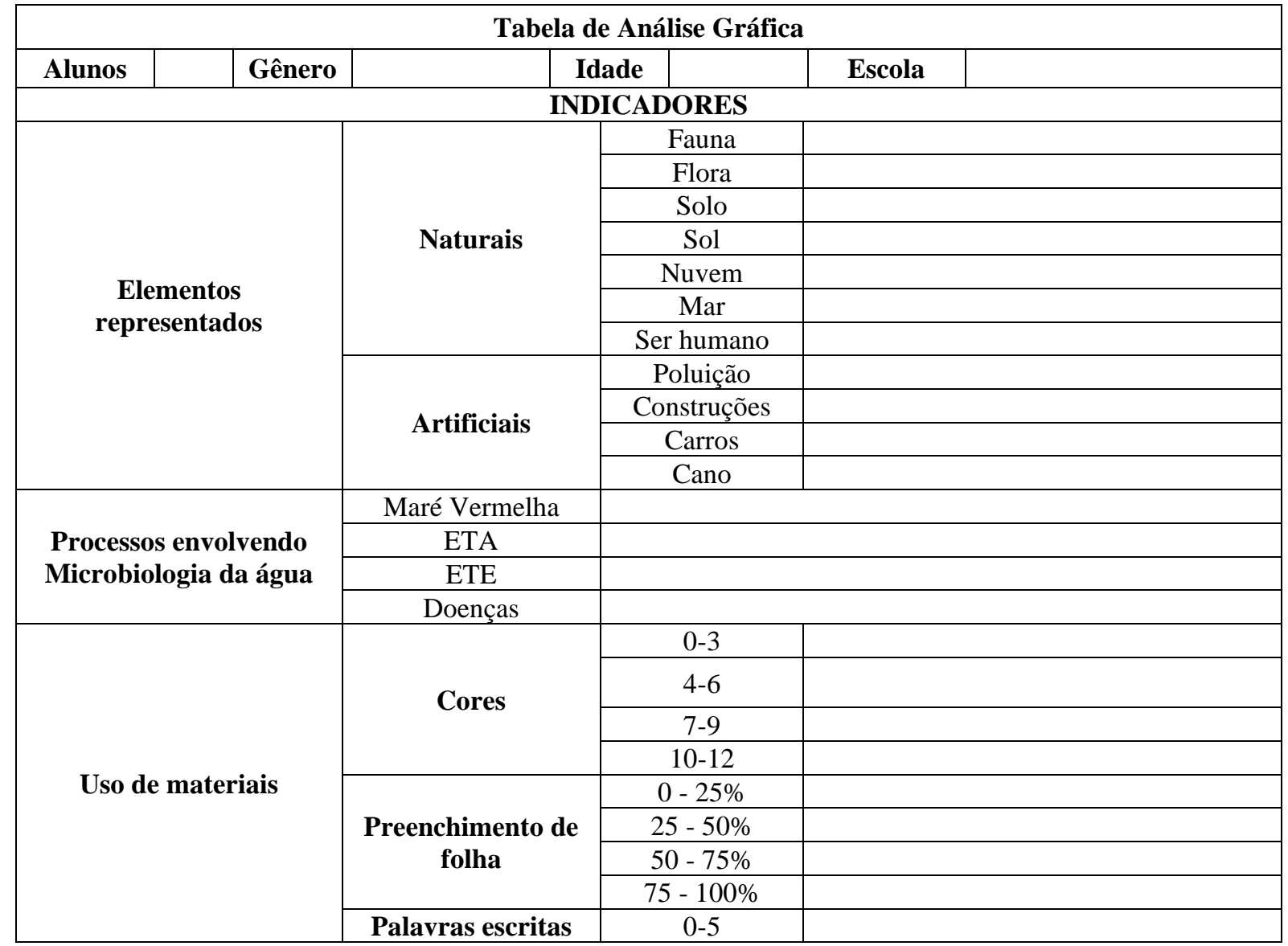

Fonte: Autores (2021).

Em seguida, as discussões foram tratadas de acordo com a literatura atual e pertinente frente à temática. Por fim, para expandir e disseminar informações, o jogo foi disponibilizado no repositório de Objetos Educacionais do Laboratório de Microbiologia da UECE com as devidas recomendações de melhorias realizadas pelos avaliadores nesta pesquisa.

\section{Resultados e Discussão}

O jogo MICROH2O - o caminho das águas, foi assim intitulado devido a inspiração em duas músicas: Encontro das Águas, de autoria do músico Jorge Vercillo, através do trecho: “A paixão veio assim afluente sem fim / Rio que não deságua / Aprendi com a dor nada mais é o amor / Que o encontro das águas”. E da música O Reino Das Águas Claras, também de autoria do músico Jorge Vercillo, com o trecho: "Vim de lá / Pela floresta de algas pude andar / Nem sei como eu vou contar / Lá no reino das águas claras / Mágico mundo de joias raras / Meu passeio mais bonito / Tantos cardumes, que maravilha.”

Dentro do contexto da concepção de seu título, o jogo MICROH2O - o caminho das águas, tem como objetivo ser uma ferramenta didática para trabalhar a temática da Microbiologia da Água, com o intuito de finalizar o jogo percorrendo o caminho por meio da conquista das estações, através da resposta a perguntas questionadoras distribuídas durante as estações do jogo.

Foi criado um logotipo (Figura 1) para profissionalizar o jogo. Foram utilizados elementos gráficos que tinham relação com o tema água, alinhando-os a um design base de tons de azul e lettering branco.

O jogo foi confeccionado com uso de componentes escolhidos por remeter visualmente aos conteúdos e se adequar à faixa etária do público alvo (a partir de onze anos de idade). Este material se exibe com um tabuleiro, cinco pinos, um dado, 
noventa e seis cartas e um manual de instruções.

Com relação ao tabuleiro (Figura 2), foi seguida uma construção do caminho em cima do conteúdo programático acerca do tema Microbiologia da Água, organizando os assuntos sequencialmente para que fosse possível construir uma conexão entre as partes do tabuleiro. Sendo assim, a forma de apresentação do jogo objetivou ser pertinente e integrar as vivências extra sala dos alunos aos temas por meio do uso dessa ferramenta didática.

Figura 1. Logotipo do jogo MICROH2O - o caminho das águas.

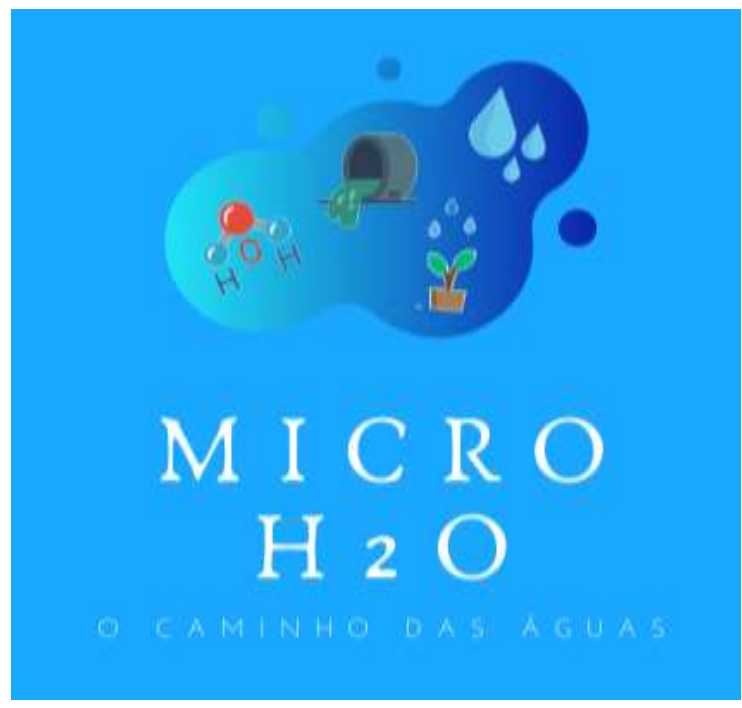

Fonte: Autores (2021).

A construção do tabuleiro foi realizada de forma digital, com auxílio dos programas gráficos, CorelDRAW Graphics Suite ${ }^{\circledR}$ e Microsoft ${ }^{\circledR}$ Publisher. O tabuleiro possui tamanho de 1,5 m x 0,8 cm tendo impressão realizada em lona de vinil. Apresenta tonalidade de plano de fundo na cor creme para que se destacassem tons variados da cartela de cor azul que foi empregue para compor as casas do tabuleiro. Também foram utilizados tons de branco, vermelho e preto para trazer mais cores para esse tabuleiro (Figura 2). 
Figura 2. Tabuleiro do jogo MICROH2O - o caminho das águas.

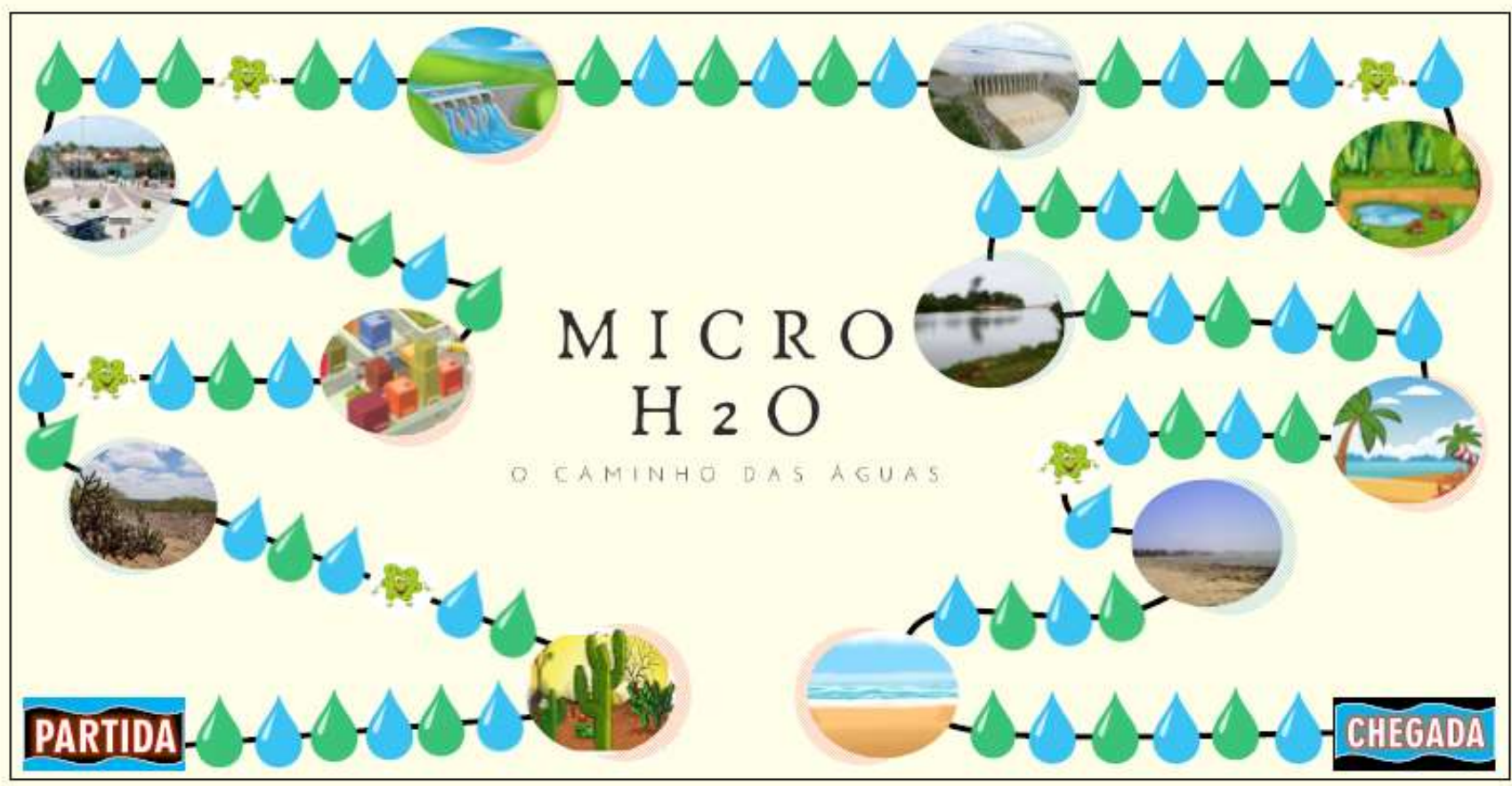

Fonte: Autores (2021).

O caminho do tabuleiro foi percorrido de acordo com o tempo disponível à aula, cinquenta minutos, podendo variar a depender do andamento das partidas e de como o professor conduzirá as jogadas. As representações gráficas alocadas foram retiradas de um banco de imagens do Google Imagens ${ }^{\circledR}$, a fim de compor as estações principais do tabuleiro, mesclando o uso de imagens reais e desenhos representativos dos seguintes espaços selecionados: Bioma da Caatinga, Cidade Urbanizada, Represa de Abastecimento, Lagoa, Praia e Mar (Figura 3).

Figura 3. Ilustrações e imagens utilizadas no tabuleiro do jogo $\mathrm{MICROH} 2 \mathrm{O}$ - o caminho das águas.
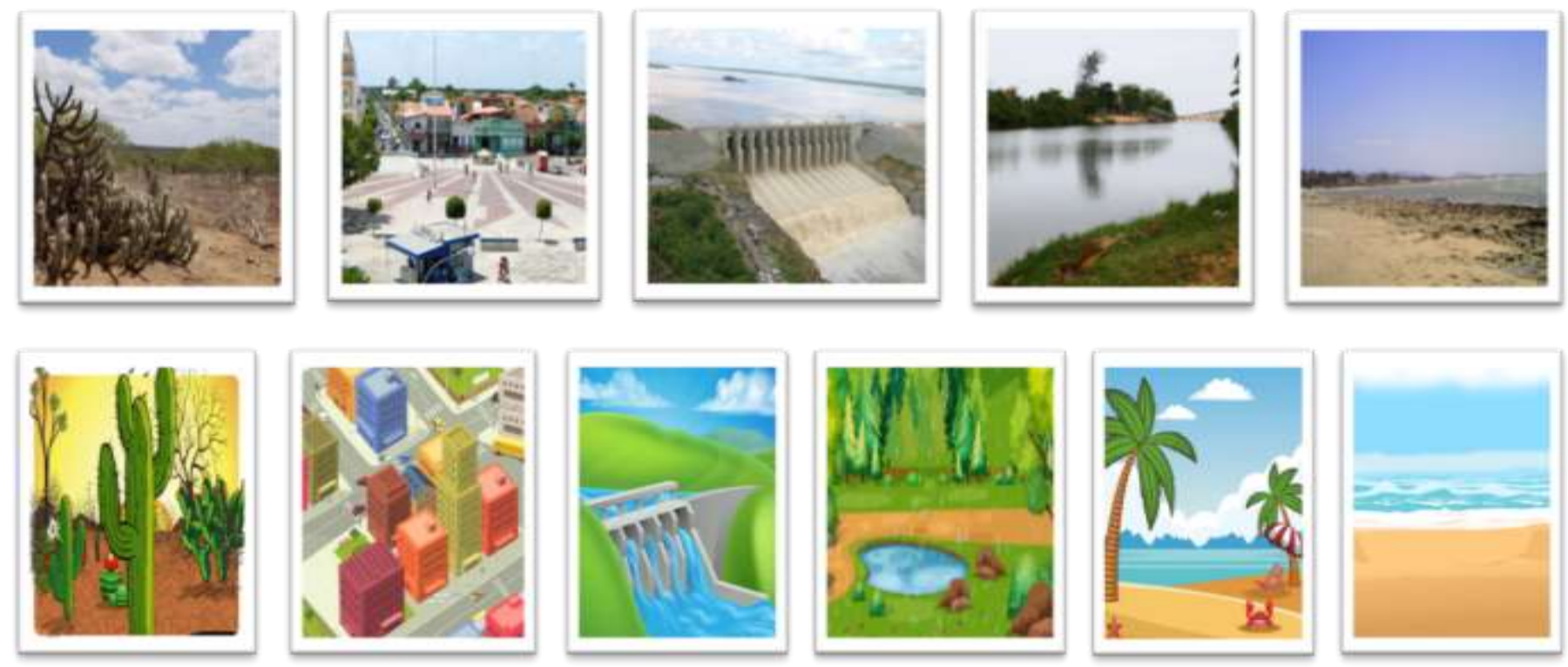

Fonte: Autores (2021). 
Utilizar imagens em jogos possibilita aproximar por meio do reconhecimento visual o assunto abordado aos brincantes, permitindo que esses analisem e interpretem conceitos abordados a partir da comparação entre as imagens e as experiências de cada grupo (Pereira, 2008).

Seguindo a divisão das estações contidas no tabuleiro, as cartas do jogo foram distribuídas em duas categorias: a primeira composta por um baralho de perguntas seguindo cada estação, contendo 81 cartas (Figura 4A e 4B) e a segunda formada por um baralho de auxílio preenchido com 15 cartas (Figura 4C e 4D) sendo apresentadas em tamanho 9,5 cm x 6,5 cm impressas coloridas em papel $80 \mathrm{Kg}$ e armazenadas em sacos plásticos com zíper (Figura 4E).

Durante a confecção foi utilizado o aplicativo Canva ${ }^{\circledR}$, onde no baralho de perguntas (Figura 4A e 4B) foi utilizado o tom verde musgo como fundo compondo-a com transparência em tons na mesma escala e designers na cor branca. A frente das cartas utiliza-se de imagens reais para cada estação mantendo o tom de verde musgo ao fundo.

Já para o baralho de auxílio (Figura 4C e 4D) foi utilizado o tom amarelo queimado seguido de bordas em tom verde musgo e desenhos gráficos que remetessem à busca por respostas, classificando-os em três tipos: Carta de Pular, Ajuda e Passe a vez. A frente das cartas segue o mesmo padrão já explicado.

$\mathrm{O}$ jogo MICROH2O - o caminho das águas encontra-se armazenado em uma caixa de papelão, que foi reciclada. A mesma foi recoberta com papel adesivo na cor azul celeste e apresenta dimensões de $6 \mathrm{~cm}$ x $34 \mathrm{~cm}$ x $36 \mathrm{~cm}$ adicionada à impressão do nome e do logotipo criado por uma designer gráfico para representar o jogo (Figura 1). 
Figura 4. Baralho jogo MICROH2O - o caminho das águas: cartas de perguntas (A e B), cartas auxiliares (C e D) e armazenamento das cartas (E).
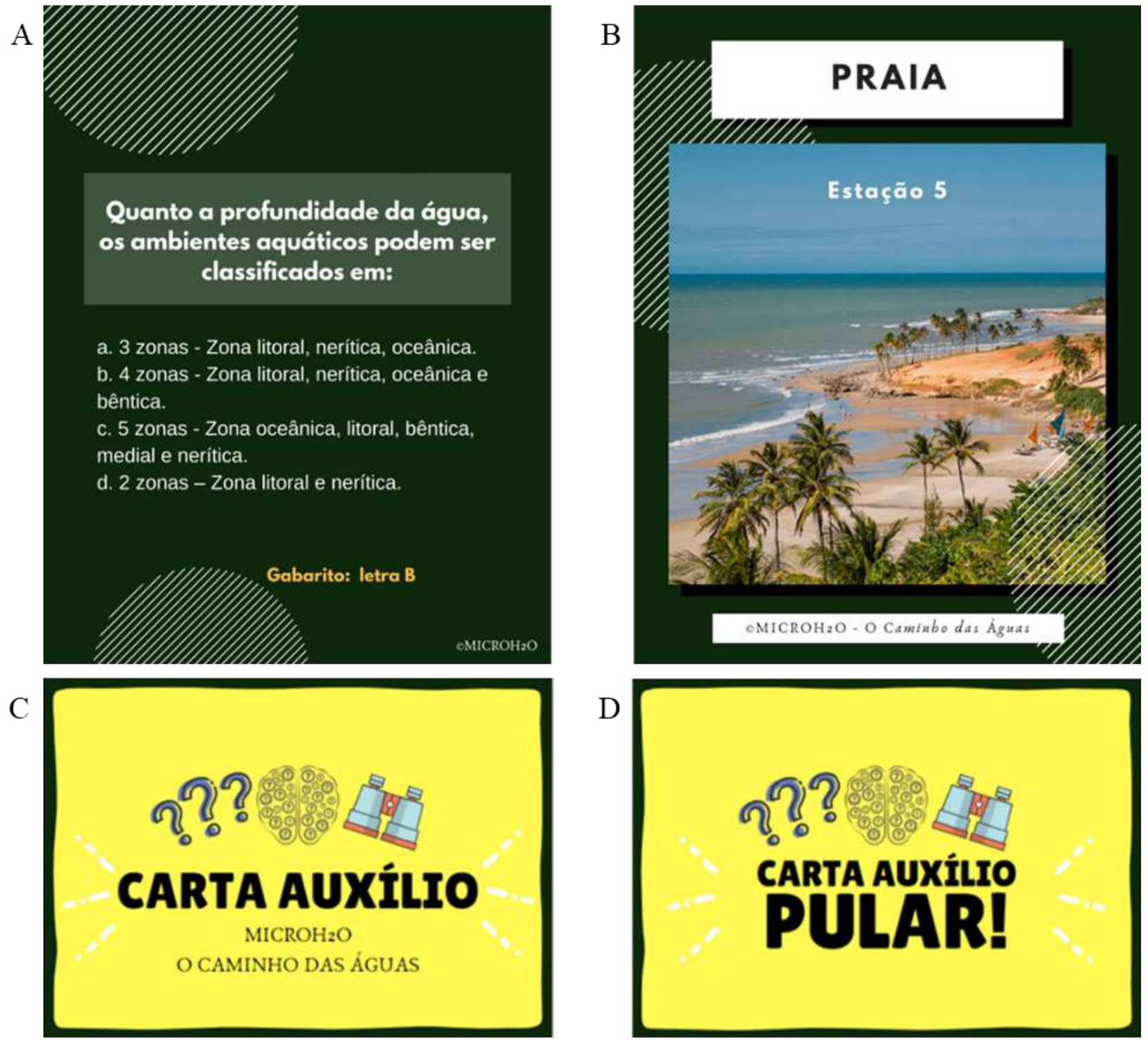

D

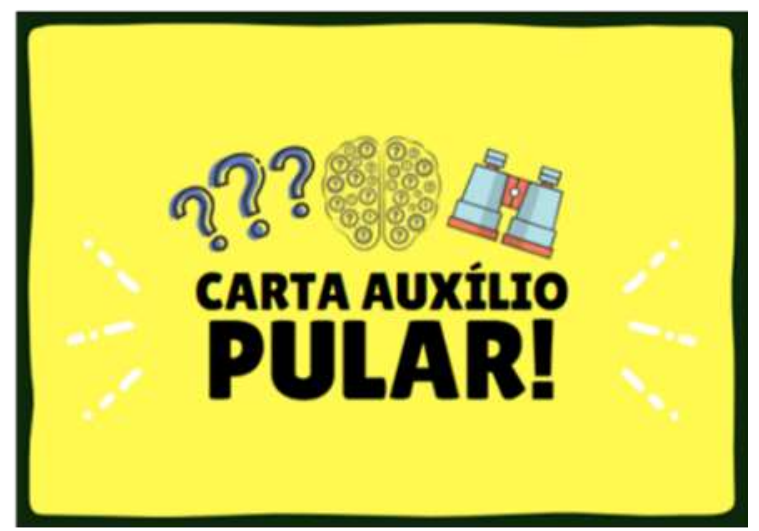

$\mathrm{E}$

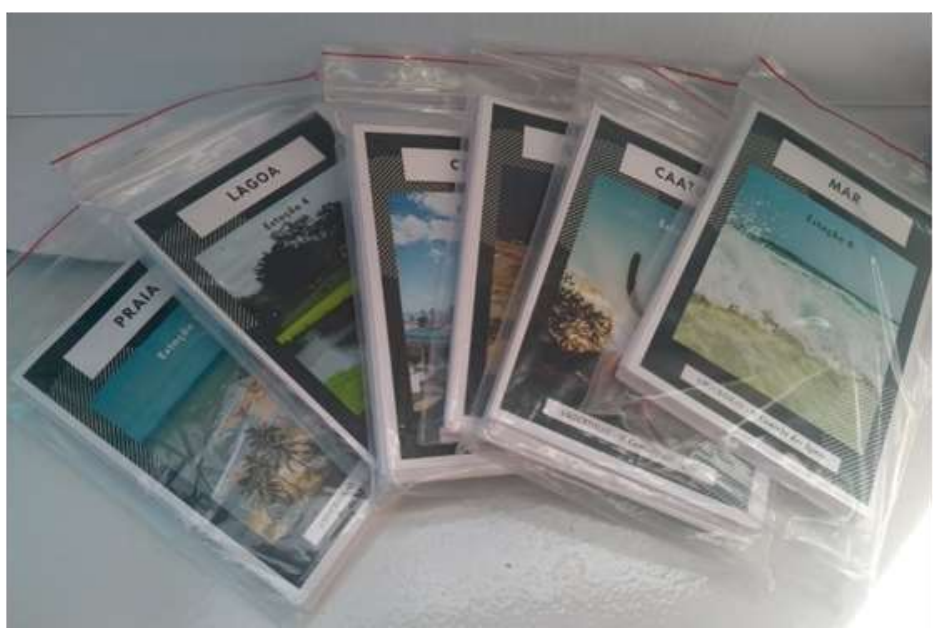

Fonte: Autores (2021).

O manual contendo as instruções do jogo foi apresentado nos anexos desse trabalho. Os outros componentes do jogo 
são: cinco pinos plásticos reciclados de outros jogos com cores amarelo, azul, verde, vermelho e preto que servirão para marcar as equipes durante o caminho do jogo e um dado.

\section{Conteúdo do Jogo}

A construção do conteúdo que foi abordado no MICROH2O - o caminho das águas, seguiu uma relação com os assuntos abordados nos livros recomendados e já analisados pelo PNLD 2017, tendo como objetivo ser uma ferramenta didática para professores adicionarem uma temática transversal ao conteúdo programático de alunos do $7^{\circ}$ Ano do Ensino Fundamental II, abordando a temática complementar sobre Microbiologia da Água.

Para isso, foram utilizados os seguintes conteúdos no jogo: recursos naturais, relações ecológicas, ecossistemas brasileiros, água e seus estados físicos, propriedades da água, água e os seres vivos, ciclo da água, água potável, conservação dos mananciais, saneamento básico (Estação de Tratamento de Esgoto - ETE e Estação de Tratamento de Água - ETA), cianobactérias, vírus, fungos, bactérias, doenças de via aquática, microrganismos patogênicos, ambientes aquáticos, poluição e contaminação da água, microrganismos aquáticos, algas e maré vermelha. Sendo estes divididos em dois níveis: o Fácil/Médio, representados pelo círculo de cor amarelo e o Médio/Difícil, representados pelo círculo de cor vermelha (Figura 5).

Figura 5. Cartas de nível médio (A) e difícil (B) do jogo MICROH2O - o caminho das águas.
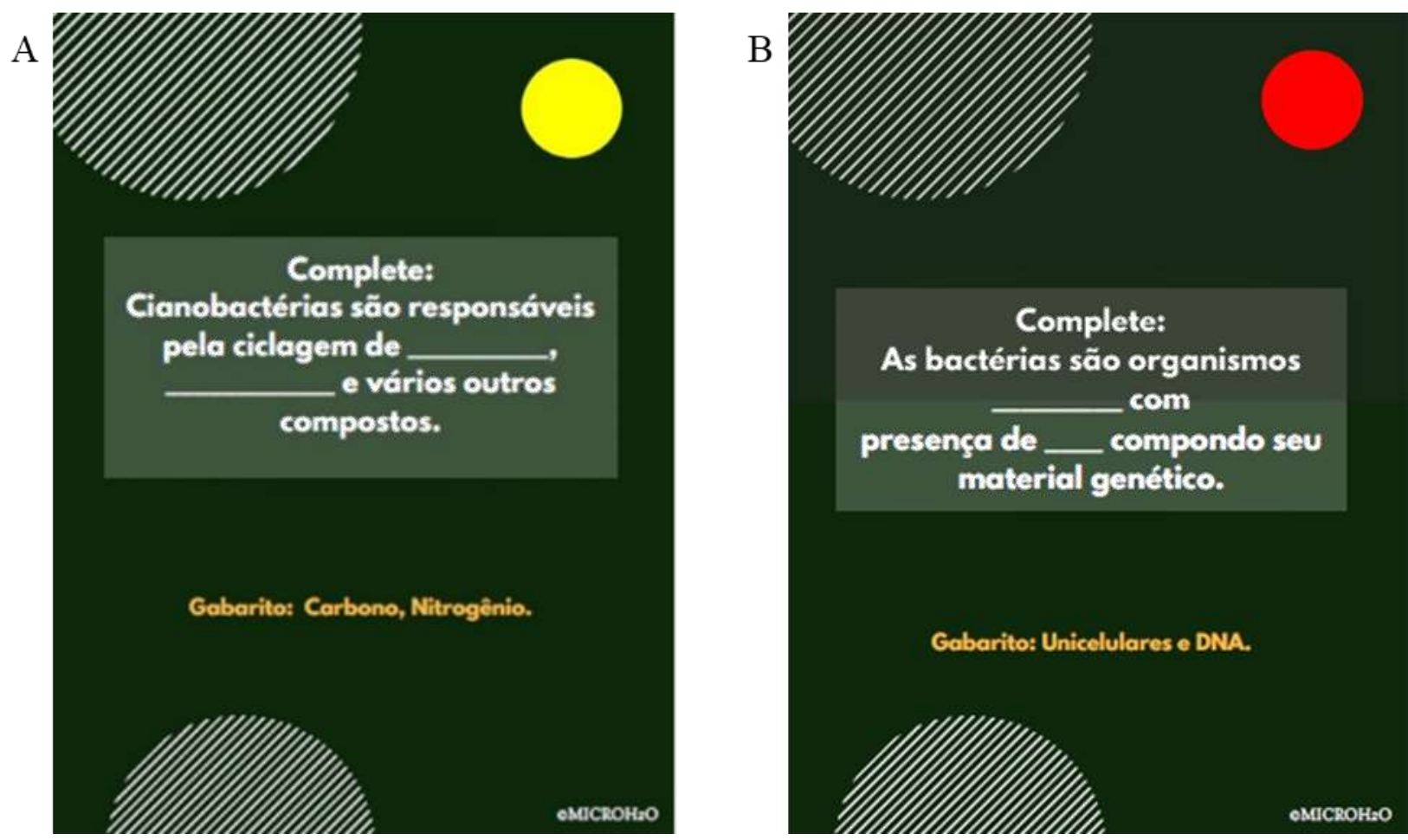

Fonte: Autores (2021).

Dessa forma, o manual do jogo é distribuído em onze categorias: informações sobre a quantidade de participantes, idade indicada, conteúdo físico (tabuleiro, baralho de perguntas e cartas auxiliares) do jogo, objetivo, conteúdo prog ramático, modo de preparo, de jogabilidade e de finalização do jogo (Figura 6). Essas informações são distribuídas em duas laudas, seguindo como parâmetro o manual do jogo Passa ou Repassa da empresa Grow®, que distribuí as informações iniciais primeiro, como: participantes, idades; e segue apresentando jogo pelos objetivos, conteúdo programático, conteúdo físico, preparação, jogabilidade e finalização. Assim, também é utilizado um conjunto de imagens que estão presentes no tabuleiro ou nas cartas do jogo, para melhorar a explicação do funcionamento do mesmo. 
Figura 6. Manual do jogo MICROH2O - o caminho das águas.

\begin{tabular}{|c|c|}
\hline & MANUAL DO JOGO \\
\hline \multicolumn{2}{|c|}{ PARTICIPANTES: 2 a 5 equipes de 6 a 10 pessoas } \\
\hline \multicolumn{2}{|l|}{ IDADE: a partir de 11 anos. } \\
\hline \multicolumn{2}{|l|}{ CONTÉm: } \\
\hline \multicolumn{2}{|c|}{01 tabuleiro $(1,5 \mathrm{~m} \times 60 \mathrm{~cm})-05$ pinos - 01 dado } \\
\hline \multicolumn{2}{|c|}{06 baralhos de pervuntss - 81 cartas verdes } \\
\hline \multicolumn{2}{|c|}{ O1 baraiho de auxxilio - 15 cutas veemethas } \\
\hline \multicolumn{2}{|c|}{01 marcador de coneuistas - lousa para marcar coneuistas da equipe } \\
\hline 2 & $\begin{array}{l}\text { OBJETIVO: facer o pino representanti da equipe ser o } \\
\text { primero a perocerer o caminho por meio da conquista das } \\
\text { estaçöes. Para conquistar essas etaçöes, as equipes } \\
\text { deverào responder as perguntas cometamente. }\end{array}$ \\
\hline \multicolumn{2}{|c|}{ 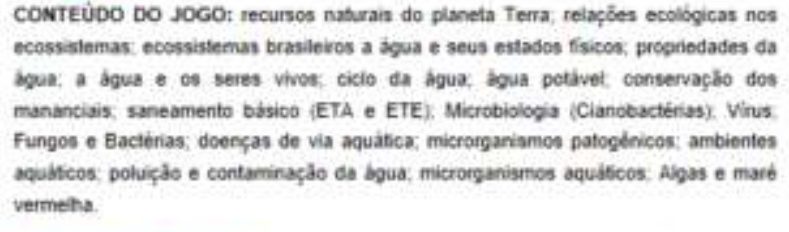 } \\
\hline 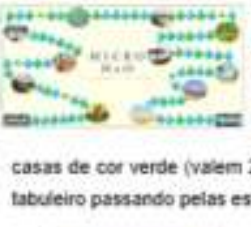 & 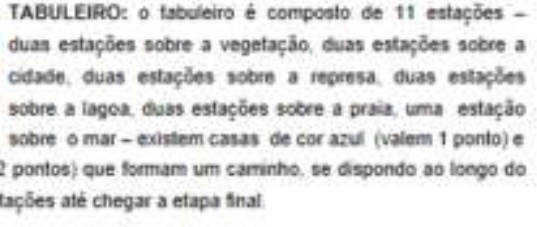 \\
\hline wost & 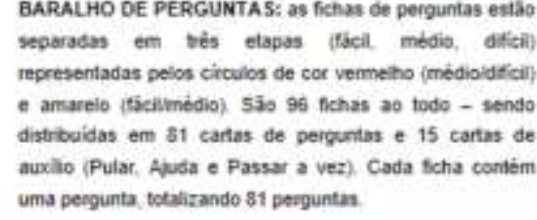 \\
\hline MICROH & $\mathrm{I}_{2} \mathrm{O}$ - O CAMINHO DAS ÁGUAS \\
\hline
\end{tabular}

\begin{tabular}{|c|}
\hline MANUAL DO JOGO \\
\hline 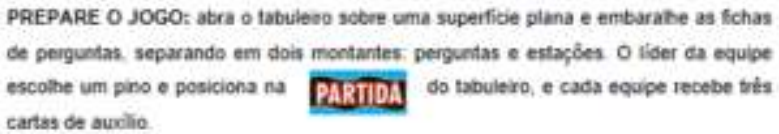 \\
\hline
\end{tabular}

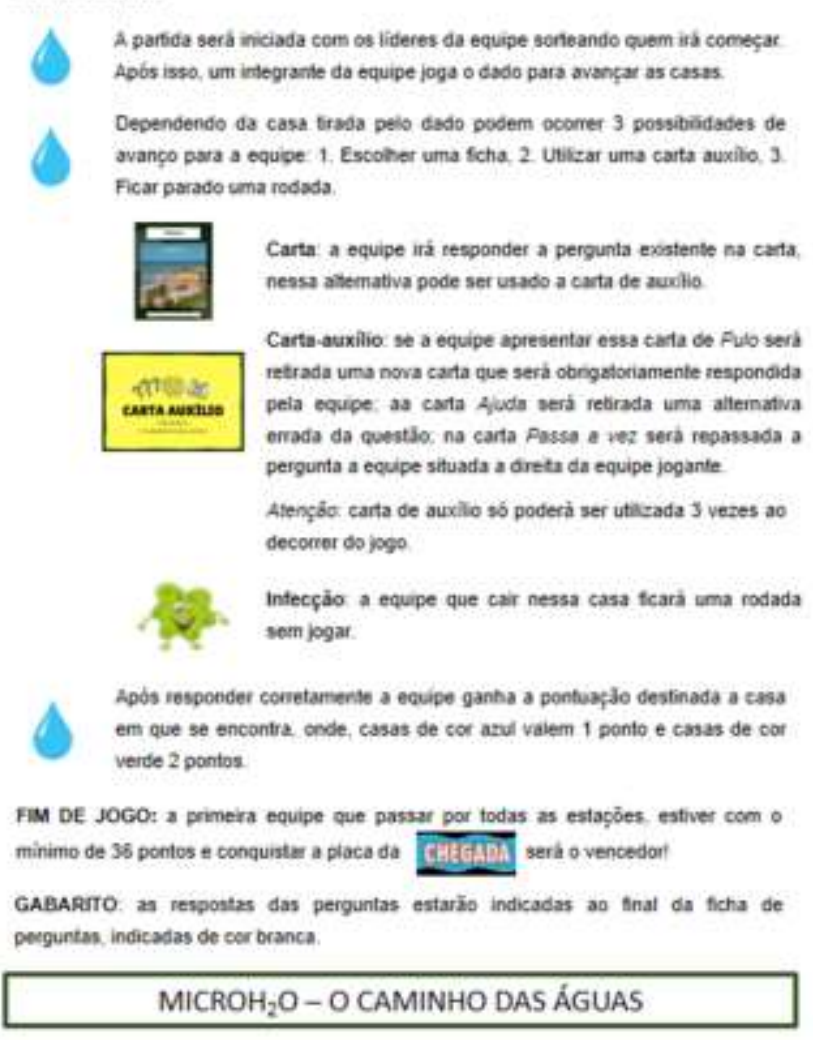

Fonte: Autores (2021).

\section{Avaliação dos Especialistas}

O total de cinco especialistas participaram da pesquisa, uma é do sexo feminino e quatro do sexo masculino, com faixa etária entre 22 a 57 anos. Três dos entrevistados exercem atividade remunerada, dois deles são formados em Ciências Biológicas, dois formados em Educação Física e um em Pedagogia. Um possui mestrado em Educação e um doutorado em Pedagogia.

Referente à organização do jogo, três especialistas analisaram a produção do mesmo e foi possível observar que dois concordaram que foi satisfatória sua organização, e que a apresentação visual estava adequada para público alvo do jogo MICROH2O - o caminho das águas, mostrando que a confecção de jogos desse tipo possibilita aos educadores explorar temáticas pouco abordadas em sala de aula, como a Microbiologia.

Bem como, também concordaram que as imagens utilizadas estavam de acordo com a temática, corroborando com o que Silva et al. (2016) relata sobre o tipo de jogo escolhido, já que os jogos de tabuleiros são bastante populares e de fácil produção e aplicação. Os especialistas ainda explanaram pontos positivos, negativos e algumas melhorias que poderiam ser realizadas no jogo. Esses escritos foram catalogados e permitiram que o jogo pudesse ser reformulado e posteriormente aplicado aos alunos do EF.

Durante a análise das respostas dos dois especialistas em conteúdo pode-se observar que, um afirma que a organização do jogo é satisfatória e o outro discorda dessa afirmação, foi relatado que as regras e a jogabilidade do jogo estavam pouco 
explícitas. Todos concordam que a apresentação visual do mesmo estava adequada para público alvo e que as imagens presentes no tabuleiro e nas cartas do jogo estavam adequadas a temática abordada.

Estes concordaram que o conteúdo abordado no jogo é muito importante, corroborando trabalho que relata em relação ao uso de novas metodologias para o ensino da Microbiologia a fim de conectar o aluno com suas experiências e que o conhecimento produza um efeito positivo e possa contribuir para a construção de um novo pensamento crítico (Antunes, Pileggi \& Pazda, 2012).

Todos discriminaram que o conteúdo foi trabalhado objetivamente e que foi realizada uma apresentação geral do conteúdo satisfatória. Também afirmaram que a temática da Microbiologia da Água foi trabalhada de maneira clara e dinâmica, tornando o assunto de fácil compreensão.

\section{Análise dos Desenhos dos Alunos}

Os desenhos foram produzidos logo após os alunos terminarem de jogar. As equipes continuaram divididas e foram distribuídas folhas de papel em branco, lápis de cor, canetas e lápis de escrever para que ocorresse a produção das representações gráficas, sendo disponibilizado para isso um tempo de 10 minutos.

A análise foi feita através de alguns critérios citados na tabela de análise gráfica (Tabela 1), aonde cada representação foi analisada individualmente, contudo, posteriormente esses resultados foram reagrupados em dois grandes grupos, os desenhos dos alunos da escola A e os desenhos de alunos da escola B, para que fosse possível realizar um comparativo entre a percepção dos alunos de cada escola. No total, foram obtidos 30 desenhos, sendo 15 da escola A e 15 da escola B.

Tabela 1. Desenho produzido pelo aluno 7 da escola A acerca do jogo MICROH2O - o caminho das águas.

\begin{tabular}{|c|c|c|c|c|c|c|c|}
\hline \multicolumn{8}{|c|}{ Tabela de Análise Gráfica } \\
\hline Alunos & 30 & Gênero & $85 \% \mathrm{~F} / 15 \% \mathrm{M}$ & Idade & 11 a 13 anos & Escola & $\mathrm{A}$ e B \\
\hline \multicolumn{8}{|c|}{ INDICADORES } \\
\hline \multirow{11}{*}{\multicolumn{3}{|c|}{$\begin{array}{c}\text { Elementos } \\
\text { representados }\end{array}$}} & \multirow{7}{*}{ Naturais } & & Gauna & & $70,6 \%$ \\
\hline & & & & & Flora & & $70,6 \%$ \\
\hline & & & & & Solo & & $50,6 \%$ \\
\hline & & & & & Sol & & $46,6 \%$ \\
\hline & & & & & Iuvem & & $62,3 \%$ \\
\hline & & & & & Mar & & $53,3 \%$ \\
\hline & & & & & humano & & $8,2 \%$ \\
\hline & & & \multirow{4}{*}{ Artificiais } & & luição & & $53,3 \%$ \\
\hline & & & & & struções & & $26,6 \%$ \\
\hline & & & & & arros & & $0 \%$ \\
\hline & & & & & Cano & & $6,66 \%$ \\
\hline \multirow{4}{*}{\multicolumn{3}{|c|}{$\begin{array}{l}\text { Processos envolvendo } \\
\text { Microbiologia da água }\end{array}$}} & Maré Vermelha & \multicolumn{4}{|c|}{$20 \%$} \\
\hline & & & ETA & \multicolumn{4}{|c|}{$13,3 \%$} \\
\hline & & & ETE & \multicolumn{4}{|c|}{$6,66 \%$} \\
\hline & & & Doenças & \multicolumn{4}{|c|}{$0 \%$} \\
\hline \multirow{9}{*}{\multicolumn{3}{|c|}{ Uso de materiais }} & \multirow{4}{*}{ Cores } & & $0-3$ & & $26,6 \%$ \\
\hline & & & & & $4-6$ & & $60 \%$ \\
\hline & & & & & $7-9$ & & $13,3 \%$ \\
\hline & & & & & $10-12$ & & $0 \%$ \\
\hline & & & \multirow{4}{*}{$\begin{array}{l}\text { Preenchimento de } \\
\text { folha }\end{array}$} & & $-25 \%$ & & $0 \%$ \\
\hline & & & & & $-50 \%$ & & $20 \%$ \\
\hline & & & & & $-75 \%$ & & $26,6 \%$ \\
\hline & & & & & $-100 \%$ & & $53,3 \%$ \\
\hline & & & Palavras escritas & & $0-5$ & & $20 \%$ \\
\hline
\end{tabular}

Fonte: Autores (2021). 
Dos 15 alunos que participaram 50\% são de sexo feminino e 50\% masculino, com faixa etária de 11 a 13 anos, e desses desenhos todos os elementos naturais selecionados na tabela foram utilizados. $66,6 \%$ dos alunos representaram elementos de fauna e flora relacionados à ecologia da Caatinga presente no jogo, bem como 46,6\% colocaram os solos e o sol de alguma maneira, seja em uma distribuição ampla ou reduzida da folha, corroborando com a ideia já apresentada durante o jogo aos discentes, de que a preservação da flora é extremamente importante para a preservação de características ambientais cruciais do bioma Caatinga (Figura 7).

Figura 7. Desenho produzido pelo aluno 7 da escola A acerca do jogo MICROH2O - o caminho das águas.

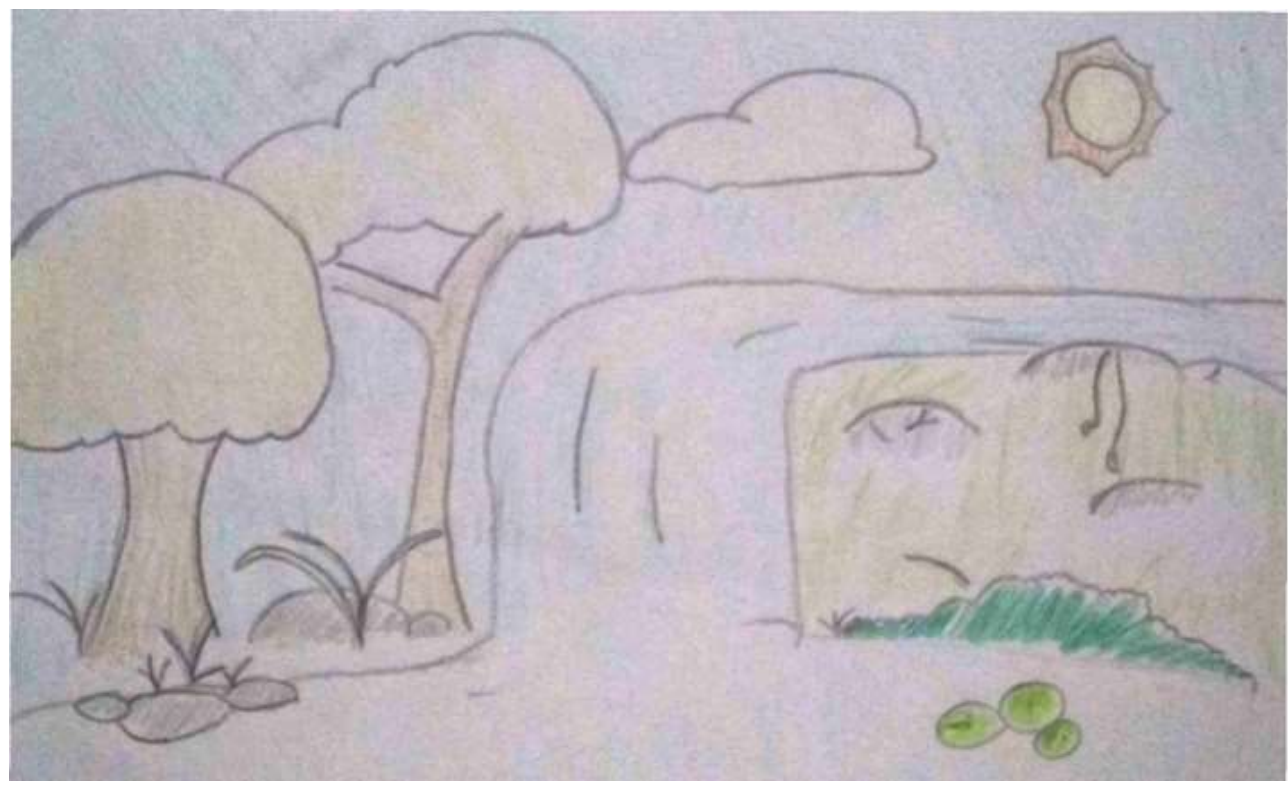

Fonte: Autores (2021).

A utilização de desenhos como uma prática inserida no ensino de Ciências vem se tornando uma ferramenta didática importante, pois apresenta aos alunos, alguns conceitos básicos da educação socioambiental, alinhados às vivências extraclasse e aos ensinamentos de Ciências, mostrando o qual relevante é para o discente experimentar recursos de ensino que incrementem a motivação em sala de aula e construam uma base para o entendimento da necessidade de se conservar os recursos existentes na natureza (Costa et al., 2018).

Dos elementos artificiais, $90 \%$ contido na tabela foi utilizado, enquanto $53,3 \%$ demonstrou a poluição, por meio do desenho de pneu, garrafa ou plástico; nenhum aluno utilizou o desenho do carro para representar o ambiente artificial. Com relação aos processos envolvendo Microbiologia da Água, 20\% demonstraram o processo da Maré Vermelha através de algas e fitoplâncton, em contrapartida foi analisado que nenhuma representação gráfica continha demonstração de alguma doença ou enfermidade. Quanto ao uso de materiais, $60 \%$ dos discentes utilizaram de 4 a 6 cores para a produção de seus desenhos observando-se uma preferência pelo uso de tons azul, verde e amarelo. 53,3\% preencheram de 75 a 100\% da folha disponibilizada e apenas $20 \%$ escreveram alguma palavra relacionada ao contexto do jogo.

Dessa maneira, é possível perceber a relevância da aplicação de recursos que estimulem a conscientização desses alunos por meio do conhecimento das vivências pessoais para que seja possível observar as mudanças no dia-a-dia dessa criança (Figura $8)$. 
Figura 8. Desenho produzido pelo aluno 7 da escola A acerca do jogo MICROH2O - o caminho das águas.

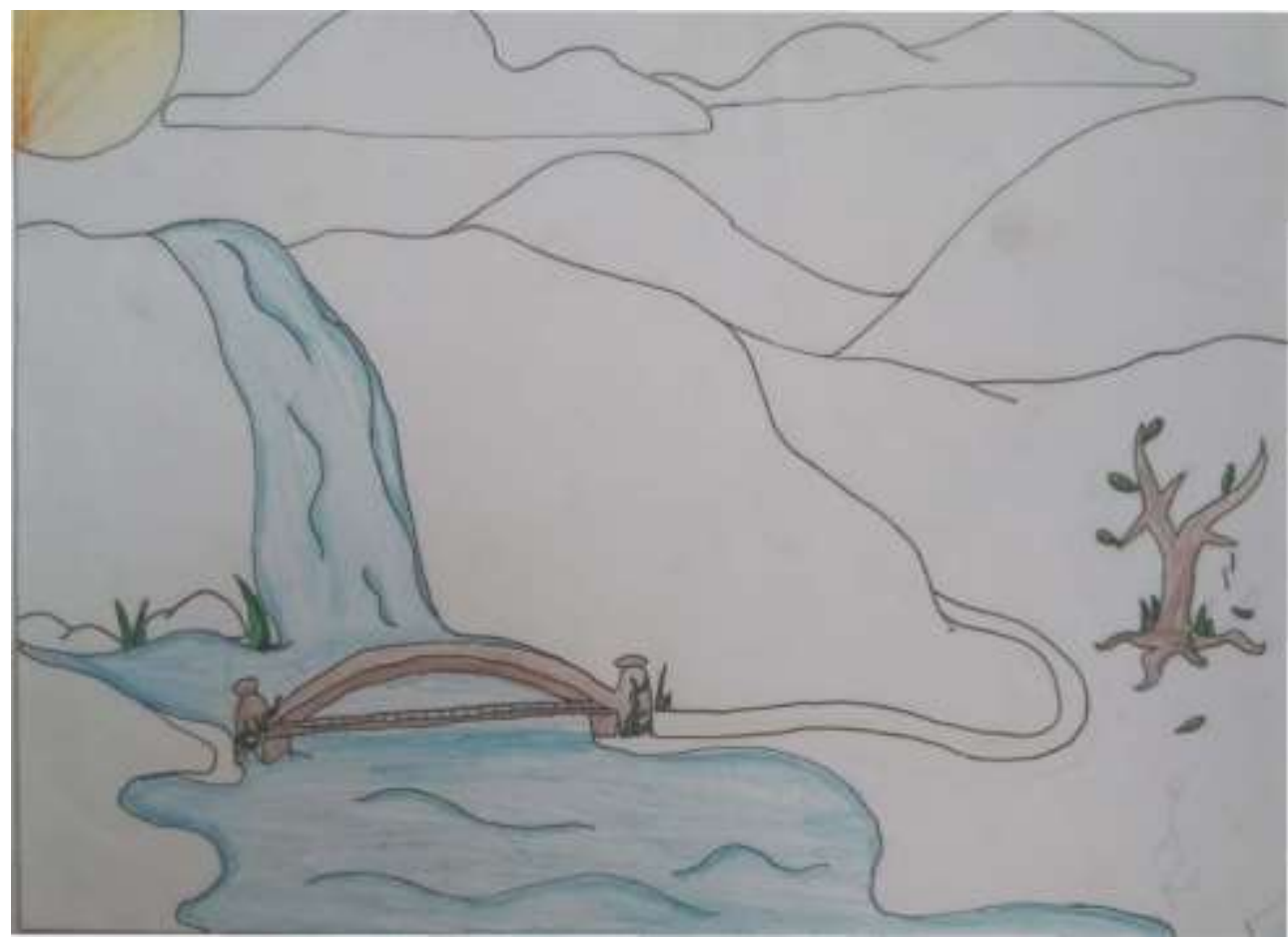

Fonte: Autores (2021).

Esse processo de conscientização se dá principalmente durante a construção do aluno dentro do espaço escolar, por meio do ensino formal e do diálogo, com intuito de apresentar alternativas para a construção de uma conscientização dialogada e cidadã, regida pelos ensinamentos de Paulo Freire, que traz à tona a partilha de saberes entre o professor e o aluno, para deixar o ensino ser um processo prático através de vivências ativas (Machado et al., 2016).

\section{Considerações Finais}

Através do jogo de tabuleiro se oportuniza que os discentes sejam agentes participativos de seu processo de ensino aprendizagem, permitindo que se conectem com as temáticas abordadas em sala de aula e modifiquem o seu conhecimento, havendo uma união de suas vivências pessoais e os ensinamentos que perpassam não só a Ciência e a Biologia, mas entrelaçamse com outras matérias estudadas em sala de aula.

É possível concluir que alinhar prática pedagógica do jogo didático ao currículo proposto para os alunos dos anos finais do Ensino Fundamental, possibilita que estes comecem a se interessar mais pelos temas abordados em sala de aula e permite que temáticas transversais e assuntos que não são tão aprofundados nesses anos sejam ali discutidos e estudados, demonstrando que existem diversas formas de se adquirir conhecimento.

Também foi possível demonstrar como os alunos são receptivos ao uso de jogo didático, que estimula e melhora a participação durante a aula. Sendo percebível como o jogo permite através do brincar acesso ao conhecimento anteriormente aprendido e que se mescla as vivências do aluno e permite a criação inicial de uma consciência ambiental que implicará em uma mudança de modos e atitudes desses futuros cidadãos.

\section{Referências}

Antunes, C. H., Pileggi, M. \& Pazda, A. K. (2012). Porque a visão científica da microbiologia não tem o mesmo foco na percepção da microbiologia no ensino médio? Anais III Simpósio Nacional de Ensino de Ciências e Tecnologia, 3(1), 1-15. 
Azevedo, V. K. S., Silva, C. A. \& Freire, L. M. (2018). Educação Ambiental na discussão sobre os usos da água no ciclo de produção de bens de consumo: desenvolvendo uma atividade didática na escola. Coleciona. Fichário do Educador Ambiental, 15(1), 1-8.

Bôas, R. C. V., Junior, A. F. N. \& De Souza M. F. M. (2018). Utilização de recursos audiovisuais como estratégia de ensino de Microbiologia do Solo nos ensinos fundamental II e Médio. Revista Práxis, 10(19), 79-90.

Campos, T. R. (2018). O Uso de Jogos Digitais no Ensino de Ciências Naturais e Biologia: Uma Revisão Bibliográfica. 104 f. Trabalho de Conclusão de Curso (Graduação em Ciências Biológicas) - Universidade Federal de Santa Catarina, Florianópolis.

Compiani, M. (2018). Comparações entre a BNCC atual e a versão da consulta ampla, item ciências da natureza. Ciências em Foco, 11(1), 91-106.

Costa, E. K. S. L., Higashikawauchi, A., Costa, E. S. L. \& Araújo, M. S. L. C. (2018). A ilustração científica no ensino de ciências como ferramenta etnobiológica. Revista Brasileira de Meio Ambiente, 4(1), 207-219.

Creswell, J. W. (2021). Projeto de pesquisa: métodos qualitativo, quantitativo e misto. (5a ed.), Penso. 923 p.

Fuzeto, A. P., De Lima, A. C., Quiarato, M. A. \& Correa, T. H. P. (2018). Desenvolvimento de jogos de tabuleiro (board game) para o ensino da aplicação dos conceitos de controle da qualidade em uma unidade industrial. Revista Principia, 1(39), 63-71.

Kimura, A. H., Oliveira, G. S. de, Scandorieiro, S., Souza, P. C. de, Schuruff, P. A., Medeiros, L. P., Bodmar, C. G., Sarmiento, J. J. P., Gazal, L. E. de S., Santos, P. M. C. dos, Koga, V. L., Cyoia, P. S., Nishio, E. K., Morey, A. T., Tatibana, B. T., Nakazato, G. \& Kobayashi, R. K. T. (2013). Microbiologia para o ensino médio e técnico: contribuição da extensão ao ensino e aplicação da ciência. Revista Conexão UEPG, 9(2), 254-267.

Machado, A. V. M., Dos Santos, J. A. N., Nogueira, L. T., Nogueira, M. T. \& De Oliveira, P. A. D. (2016). Acesso ao abastecimento de água em Comunidades Rurais: o desafio de garantir os direitos humanos à água. Anais XII Congresso Nacional de Excelência em Gestão \& III INOVARSE-Responsabilidade Social Aplicada, 1, 1-14

Machado, G. E., Vestena, N. P. \& Folmer, I. (2016). (Re) uso da água da chuva: experiência no Colégio Politécnico de Santa Maria (RS). Revista Brasileira de Educação Ambiental (RevBEA), 11(5), 10-18.

Manzato, A. J. \& Santos, A. B. (2012). A elaboração de questionários na pesquisa quantitativa. Departamento de Ciência de Computação e Estatística-IBILCEUNESP, 1-17.

Medeiros, L. P., Scandorieiro, S., Kimura, A. H., Marques, L. A., Gonçalves, G. D., Aranome, A. M. F., Nakazato, G., Morey, A. T. \& Kobayashi, R. K. T. (2017). Reconhecendo a Microbiologia no nosso dia a dia pelo método PBL por estudantes do ensino médio. Luminária, 19(1), 34-43.

Pascotto, M. C. \& Montalvão, L. G. (2020). Jogos didáticos: importância e contribuição para o processo de ensino-aprendizagem de ciências e biologia. Revista Panorâmica online, 31(1), 189-206.

Pereira, R. F. (2008). Desenvolvendo jogos educativos para o ensino de física: um material didático alternativo de apoio ao binômio ensino-aprendizagem. 153 f. Dissertação de Mestrado. Universidade Estadual de Maringá, Curitiba.

Ramos, D. K., Ribeiro, F. L., Anastácio, B. S. \& Da Silva, G. A. (2019). Elaboração de questionários: algumas contribuições. Research, Society and Development, $8(3), 1-13$.

Santos, J. L. G., Erdmann, A. L., Meirelles, B. H. S., Lanzoni, G. M. M. L., Cunha, V. P. \& Ross, R. (2017). Integração entre dados quantitativos e qualitativos em uma pesquisa de métodos mistos. Texto Contexto Enferm, 26(3), e1590016.

Silva, K. J. F., Sobreira, A. C. M., Bezerra, M. A., Silva, M. O. \& Martins, M. M. M. C. (2016). A Utilização de Jogos Didáticos no Ensino Biologia: Uma Revisão de Literatura. Anais III Congresso Nacional de Educação - III CONEDU, 1(1), 1-10. 